\title{
Fingerprinting of Gold Artefacts from Mapungubwe, Bosutswe and Thulamela
}

\author{
B Grigorova, W Smith, $K$ Stülpner, and J A Tumilty \\ Anglo American Research Laboratories (Pty) Ltd, PO Box 106, Crown Mines, 2025, South Africa \\ and $D$ Miller \\ Archaeology Department, University of Cape Town, Private Bag, Rondebosch, 7700
}

\begin{abstract}
The AARL gold fingerprinting technology has been applied to the analysis of gold artefacts excavated from the southern African sites of Mapungubwe, Bosutswe and Thulamela. Information gleaned from this process is relevant to studies conducted into artefact origins and provides increased insight into the history of this region with regards to the mining, cultural and trade practices associated with these early communities.
\end{abstract}

The history of metallurgy and metal ore mining in southern Africa is thought to date back at least 2000 years. Prospecting for iron ore and malachite by indigenous farming communities during the 1st millenium $A D$, together with gold and tin ore at the start of the 2nd millenium AD had important economic and social implications. Production of these metals to manufacture jewellery, ingots, implements and a variety of other artefacts led to the establishment of wealthy intra- and intercontinental trading towns such as Mapungubwe and Great Zimbabwe. The export of iron, copper, gold and tin from southern Africa via the Indian Ocean trade network in exchange for glass beads and other luxury goods is evidence of economic contact with North Africa, the Middle East, India and China. Such intercontinental trading flourished from about $\mathrm{AD} 800$ and is marked by a significant increase in metal production at the start of the 2nd millenium AD. Metal mining and metallurgy were therefore pivotal in urbanisation, social structuring and state formation $(1,2)$.

A series of seventy-six gold artefacts from Mapungubwe, Bosutswe and Thulamela archaeological sites kept in the Department of Archaeology, University of Cape Town, were examined using the AARL gold fingerprinting technology (3). This process adopts a qualitative approach utilizing laser ablation inductively coupled plasma spectrometry (LA-ICPMS) as the means for sample analysis. LA-ICP-MS ensures sufficient sensitivity and resolution to allow detection of major, minor and trace elements from ${ }^{45} \mathrm{~S} \mathrm{c}$ to ${ }^{238 \mathrm{U}}$. The profiles generated are a function of signal intensity and subsequent source discrimination is based on elemental comparisons of sample profiles on a presence/absence basis together with differences in their corresponding lead isotope ratios. The analyses were conducted with the view to obtaining more information regarding gold composition and its derivation from single or multiple sources as well as tracing possible trade between various sites.

The AARL gold fingerprinting technology is appropriate for the analysis of gold artefacts as it is essentially a non-destructive technique with sufficient sensitivity to investigate the full element range from lithium through to thorium and uranium. Fingerprinting is currently used to determine the provenance of gold bullion and this analysis provides the first instance of its use in the study of gold artefact origins.

The Mapungubwe archaeological site is situated in South Africa at the confluence of the Limpopo and Sashi Rivers and dates back to the 10th - 13th centuries AD. Although the manufacture of jewellery predominated, this early 2 nd millenium site shows the first appearance of large iron agricultural tools and weapons other than small arrow heads. Mapungubwe, with its evident wealth, is thought to have been one of the major towns which dominated the Indian Ocean trade in southern Africa. The gold artefacts (Figure 1), including the famous gold rhinoceros, different types and sizes of gold beads, spirally wound strips, beaten 


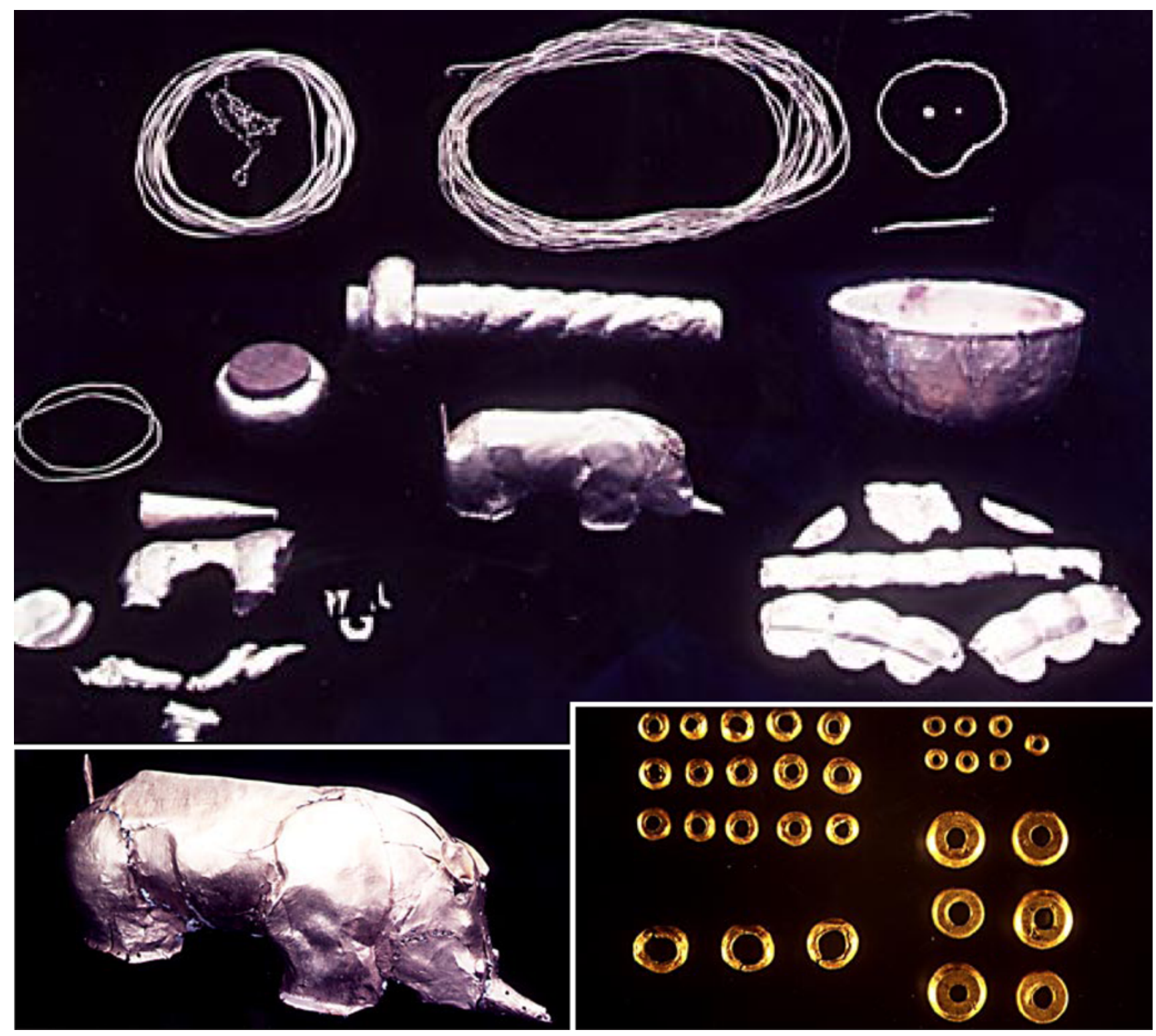

Figure 1 Gold Artefacts from Mapungubwe

sheets, wire and minute gold tacks, were all excavated from elite burial sites at the top of the Mapungubwe hill and constitute the oldest known gold in South Africa.

Bosutswe, a hill-top site in south-east Botswana, dates from the 8 th -13 th centuries AD. A single piece of gold wire from levels containing Mapungubwe style pottery was available for the fingerprinting exercise. Investigations were focused on determining whether Mapungubwe was the origin of the gold used to produce this wire, thus suggesting a possible trade link between these two centres.

The third archaeological site of interest, Thulamela, is situated in the Kruger National Park near the confluence of the Luvuvhu and Limpopo Rivers and dates back to the 14 th - 16 th centuries AD. Iron, copper, gold (numerous gold beads, a wound gold bangle and melting crucible sherds with adhering gold droplets) and other metal artefacts excavated from this area indicated cultural links between the inhabitants of Thulamela, Mapungubwe and Great Zimbabwe (4). Also recovered were glass beads and oriental ceramics which provide evidence that Thulamela was involved in the Indian Ocean trade network.

The artefacts received were all analysed for 130 isotopes with representative fingerprint profiles for 
Mapungubwe, Bosutswe and Thulamela being given below in Figure 2.

The results revealed that all the artefacts contained similar levels of silver and copper with elements such as strontium, bismuth, barium and mercury being primarily used for distinguishing gold from the three sources. Profiles for the Mapungubwe artefacts provided evidence for the existence of two different sources, M1 and M2, based on the presence or absence of strontium, mercury, barium, platinum group metals (PGMs) and rare earth elements (REEs). M1 is shown to contain all of these while M2 shows a marked absence of former three and intermittent presence of the PGMs. The fingerprint profile corresponding to the Thulamela artefacts showed a remarkable similarity to that of Mapungubwe group M1 with the presence of all the M1 distinguishing elements. The conclusion could therefore be drawn that both the Mapungubwe group M1 and Thulamela artefacts originated from the same gold source. The fingerprint obtained from the Bosutswe artefact was unique in containing only copper, silver, barium and bismuth and showed no similarities to the profiles generated for the Mapungubwe gold artefacts. However, a more conclusive evaluation of the origin of gold used in the Bosutswe artefact could be made if a greater number of samples from this site were fingerprinted. Figure 3 is a flow chart illustrating the process of artefact grouping from the three archaeological sites, based on the data obtained from the AARL gold fingerprinting technology.

Calculations of lead isotope ratios for the artefacts from Mapungubwe, groups M1 and M2, Bosutswe and Thulamela were carried out and compared to the natural ${ }^{206} \mathrm{~Pb}:{ }^{207} \mathrm{~Pb}$ ratio. Bosutswe artefacts, having a natural lead isotope profile, once again showed a difference from those excavated from Mapungubwe (M1 and M2) and Thulamela (Figure 4).

The results have clearly shown that while certain artefacts from Mapungubwe come from one gold source, other come from a different source common to that of the Thulamela gold thus suggesting access to the same source. The gold wire from Bosutswe, however, shows no links to gold originating from either Mapungubwe or Thulamela.

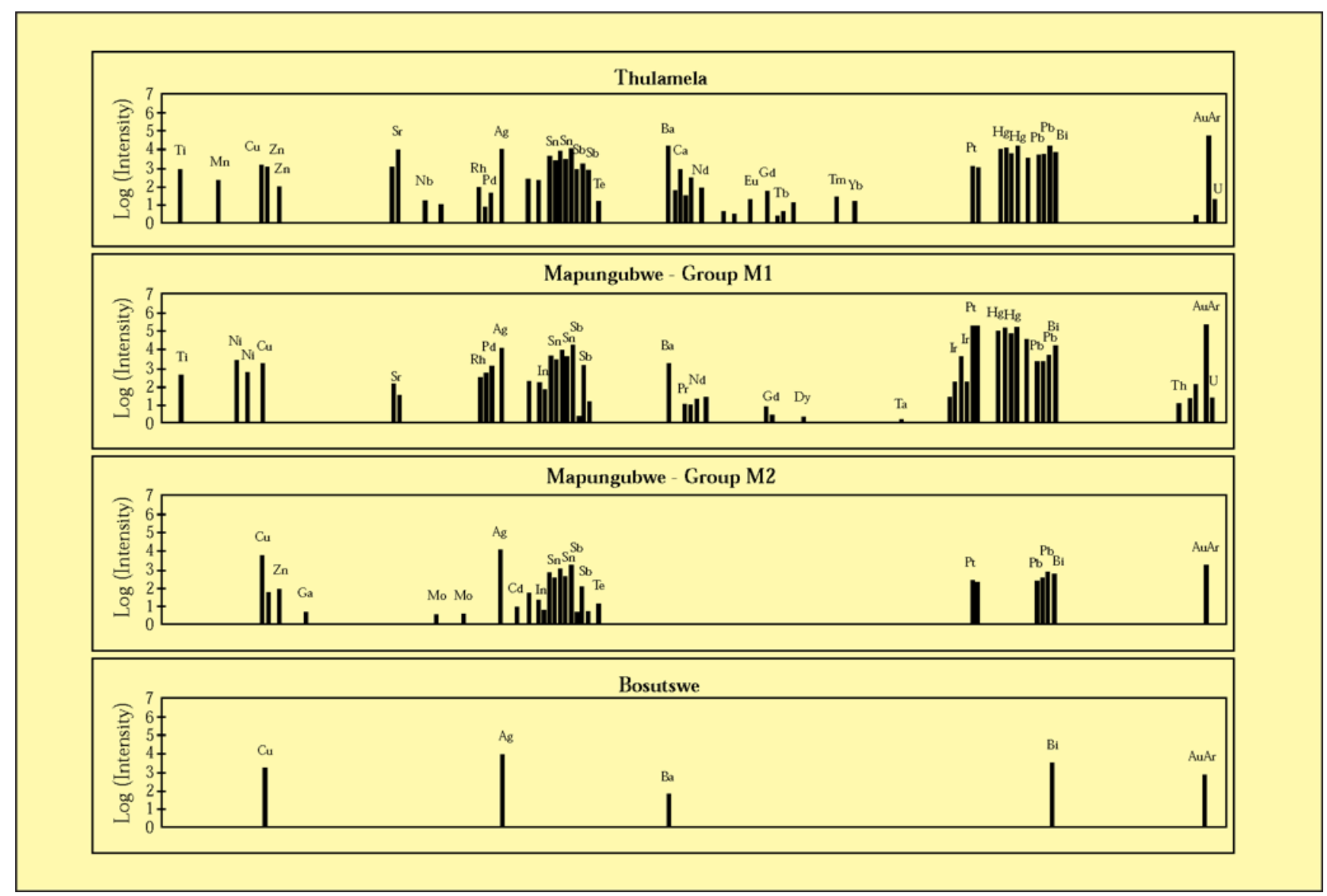

Figure 2 Fingerprint profiles of gold artefacts 


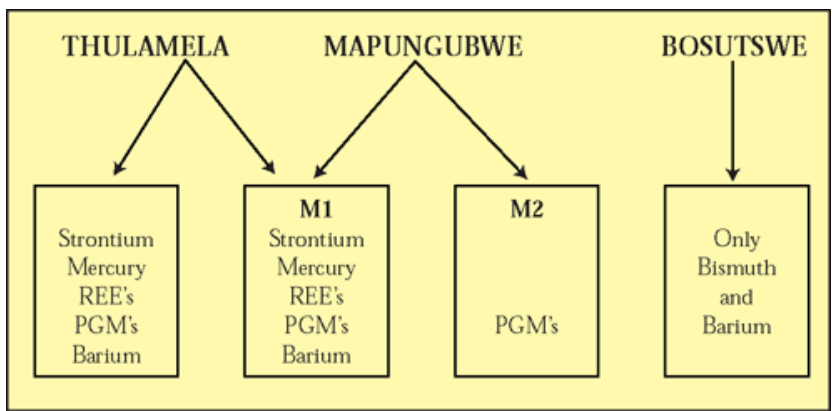

Figure 3 Flow chart showing artefact grouping

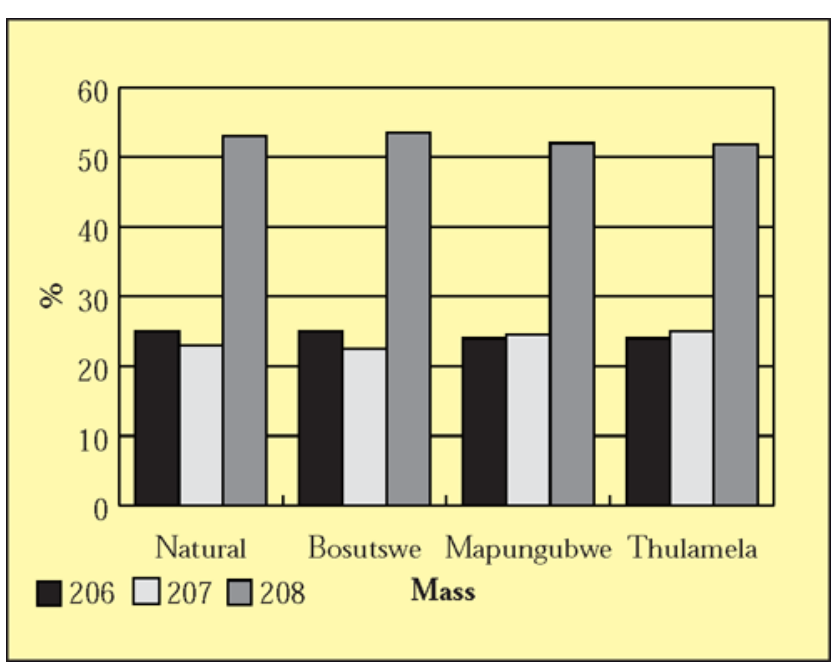

Figure 4 Lead isotope profiles

The AARL gold fingerprinting technology has been successful in determining the presence or absence of a host of elemental isotopes in artefacts from different archaeological sites. The results from the fingerprinting exercise provide information regarding both artefact gold sources and intracontinental trading practices which occurred in the early 2 nd millenium AD.

\section{ACKNOWLEDGMENTS}

We wish to thank the South African National Parks Board and Pretoria University for access to the samples.

\section{ABOUT THE AUTHORS}

Jim Tumilty is the Managing Director and Dara Grigorova the Manager Research at the AARL. Wyatt Smith is an integral member of the gold fingerprinting research team and performed the analyses and data assessment studies of the gold artefacts. Dr Duncan Miller is a Chief Research Officer in the Archaeology Department at the University of Cape Town and supplied the AARL with both the artefacts and a detailed history of the various excavation sites. Katherine Stülpner is a member of the LA-ICP-MS research team and is actively involved in research on the UV laser system.

\section{REFERENCES}

1 D. Miller, South African Journal of Geology, 1995, 98 (2), 232

2 A. Oddy, Gold Bull., 1984, 17, 70

3 B. Grigorova, S. Anderson, J. de Bruyn, W. Smith, K. Stülpner and A. Barzer, Gold Bull., 1998, 31, 26

4 M. Küsel, Koedoe, 1992, 35 (1), 55

\section{REFERENCES - for article beginning on page 75 (F C Levey et al)}

1 C.T. Heycock and F.H. Neville, Phil. Trans A, 1914, 214, 267-276 \& plates 4\&5

2 'Binary Alloy Phase Diagrams', ed. T.B. Massalski, ASM, USA, 1987, 88, 90,92

3 F.C. Levey, M.B. Cortie and L.A. Cornish, Journal de Physique IV, 1995, C8-10871092

4 I.M. Wolff and M.B. Cortie, Gold Bull, 1994, 27 (2), 44-54

5 I.M. Wolff and V.R. Pretorius, Gold Technol., 1994, 12, 7-11

6 M. Cortie, I. Wolff, F. Levey, S. Taylor, R.Watt, R. Pretorius, T. Biggs and J. Hurly, Gold Technol., 1994, 14, 30-36

7 M.B. Cortie and C.E. Mavrocordatos, Met. Trans. A, 1991, 22A, 11-18
8 C.M. Wayman, Noble Metal Alloys, AME, USA, 1986, 181-196

9 P. Vilaars and L.D. Calvert, Pearson's Handbook of Crystallographic Data for Intermetallic Phases, ASM, Metals Park, Ohio, 1985

10 R. Resnick and D. Halliday, Physics, John Wiley \& Sons, New York, 1966

11 Metals Handbook, 8th ed, ASM, USA, 1, 1966, p 19

12 R.T. Owen, Gold Technol., 1993, 10, 2,6

13 K.E. Saeger and J. Rodies, Gold Bull., 1977, 10 (1), 10-14

14 E.M. Wise, 'Gold - Recovery, Properties, and Applications', D. Van Nostrand Company, New York, 1964, 88-89 